\title{
Aortic dissection and hypothermic arrest in a Jehovah's Witness patient: a case for recombinant factor VIIa?
}

\section{[Dissection aortique et asystolie sous hypothermie chez un Témoin de Jéhovah : un} cas pour le facteur VIIa recombinant?]

Jenifer Ballen MD BSC (HONS), Michael Raabe MD FRCSC, Brian Muirhead MD FRCPC

Purpose: To present a case of survival of a cognitively intact Jehovah's Witness patient with an aortic dissection who underwent hypothermic arrest. Recombinant factor Vlla, but no blood products were administered.

Clinical features: An 83-yr-old female with an acute type A aortic dissection underwent emergent surgical repair. Proximal extension of the dissection necessitated prolonged cardiopulmonary bypass (CPB) and hypothermic circulatory arrest. Despite this, perioperative hemostatis was adequate. Recombinant factor Vlla $90 \mu \mathrm{g} \cdot \mathrm{kg}^{-1}$ iv was administered post-CPB. The patient had an uneventful postoperative course, and was discharged home neurologically intact.

Conclusions: Patients who conscientiously object to the transfusion of blood products may present a considerable anesthetic challenge, especially those at risk from coagulopathy associated with CPB and hypothermic circulatory arrest. Recombinant factor VIla may play a role in hemostasis management of these individuals, however, well-designed randomized controlled trials need to be undertaken to establish the efficacy and risks related to this potential indication.

Objectif : Présenter le cas d'un Témoin de Jéhovah qui a subi un asystolie sous hypothermie lors d'une dissection aortique et qui a survécu avec des fonctions cognitives intactes. Le facteur VIla recombinant a été administré, non des produits sanguins.

Éléments cliniques: Une femme de 83 ans a été opérée d'urgence pour la réparation d'une dissection aortique aiguë de type A. L'extension proximale de la dissection a nécessité une circulation extracorporelle (CEC) prolongée et un arrêt hypothermique.
Malgré cela, l'hémostase périopératoire a été adéquate. Le facteur VIla recombinant, $90 \mu \mathrm{g} \cdot \mathrm{kg}^{-1}$ iv, a été administré après la CEC. La patiente n'a subi aucun déficit neurologique.

Conclusion : Les patients qui refusent volontairement la transfusion de produits sanguins peuvent représenter un défi anesthésique considérable, surtout s'ils sont à risque de coagulopathie associée à la CEC et à l'asystolie hypothermique. Dans ces cas, le facteur VIla recombinant peut jouer un rôle dans l'atteinte d'hémostase, mais des études randomisées et contrôlées devront déterminer l'efficacité et les risques reliés à cette utilisation possible.

A $\mathrm{N}$ acute Stanford type A aortic dissection (one that involves the ascending aorta) is a life-threatening medical condition. Patients have a poor prognosis despite heroic medical or surgical treatment. ${ }^{1}$ Mortality approaches $60 \%$ when surgery is not attempted, while it exceeds $25 \%$ in patients who undergo surgery. ${ }^{2}$ Platelet and coagulation factor dysfunction arising from cardiopulmonary bypass $(\mathrm{CPB})$ are compounded by the institution of hypothermic arrest. ${ }^{3}$ This problem is routinely managed with allogeneic blood product transfusion. In the case of a Jehovah's Witness (JW) patient, this is not an option.

Perioperative hemostasis may be achieved with alternative agents such as recombinant factor VIIa (rFVIIa). Originally developed for the management of bleeding in hemophiliac patients with inhibitors, reviews have been

From the Department of Anesthesia, Health Sciences Centre, University of Manitoba, Winnipeg, Manitoba, Canada.

Address correspondence to: Dr. Brian Muirhead, GH611, Department of Anesthesia, General Health Sciences Centre, 820 Sherbrook Street, Winnipeg, Manitoba R3A 1R9, Canada. Phone: 204-787-4816; E-mail: bmuirhead@hsc.mb.ca Competing interests: None.

This article is accompanied by an editorial. Please see Can J Anesth 2006; 53: 336-8. 
published citing its efficacy in treating non-hemophiliac patients in the perioperative setting. ${ }^{4-6}$ Unfortunately, limited information exists regarding the use of rFVIIa in cardiac surgery patients. ${ }^{7}$

We present a case report of a JW patient undergoing hypothermic arrest and prolonged $\mathrm{CPB}$ for repair of type A aortic dissection. She survived, neurologically intact. Her care involved administration of rFVIIa without administration of blood products. Written informed consent was obtained from the patient involved in this case report, in accordance with Institutional Ethics Board policies.

\section{Case report}

An 83-yr-old female JW presented to a peripheral hospital with an acute type A aortic dissection. On computed tomography, the dissection extended to the pericardium and appeared to compress the pulmonary artery. Twenty-four hours after first presentation, the patient was transferred to a tertiary care hospital where a cardiac surgeon recommended operative repair. The patient agreed to proceed, provided there would be no transfusion of stored autologous, allogeneic, or fractionated blood products. She did agree to the administration of rFVIIa, should it be deemed necessary, despite being forewarned of its potential for thromboembolic complications.

The anesthesia team confirmed a medical history significant only for untreated hypertension. On examination there was evidence of mottling of the head and neck. Vital signs were as follows: heart rate 90 beats. $\mathrm{min}^{-1}$, blood pressure $129 / 85 \mathrm{mmHg}$ (right arm) $126 / 89 \mathrm{mmHg}$ (left arm), respiratory rate 20 breaths $\mathrm{min}^{-1}, \mathrm{O}_{2}$ saturation $98 \%\left(12 \mathrm{~L} \cdot \mathrm{min}^{-1}\right.$ nonrebreathing mask). She was alert and oriented with no focal neurologic signs. Examination was otherwise unremarkable. Preoperative hemoglobin and platelets were $132 \mathrm{~g} \cdot \mathrm{L}^{-1}$ and $142 \times 10^{9} \cdot \mathrm{mL}^{-1}$, respectively. Coagulation status was normal. Electrolytes, liver enzymes and liver function tests were also normal.

General anesthesia was induced with sufentanil 20 $\mu \mathrm{g} i v$, propofol $50 \mathrm{mg} i v$, and rocuronium $50 \mathrm{mg}$ iv and maintained with isoflurane 0.4 to $0.8 \%$ end-tidal concentration. The first activated clotting time (ACT), measured immediately following induction, was 196 sec. Heparin $500 \mathrm{U} \cdot \mathrm{kg}^{-1}$ iv was administered prior to the institution of $\mathrm{CPB}$. Five minutes after the administration of heparin the ACT was $598 \mathrm{sec}$. A loading dose of 2 million kallikrein inhibitor units (KIU) aprotinin and additional narcotic and muscle relaxant were also administered prior to institution of $\mathrm{CPB}$. Aprotinin $500,000 \mathrm{KIU} \cdot \mathrm{hr}^{-1}$ was infused after a loading dose, and the infusion was maintained until chest closure.

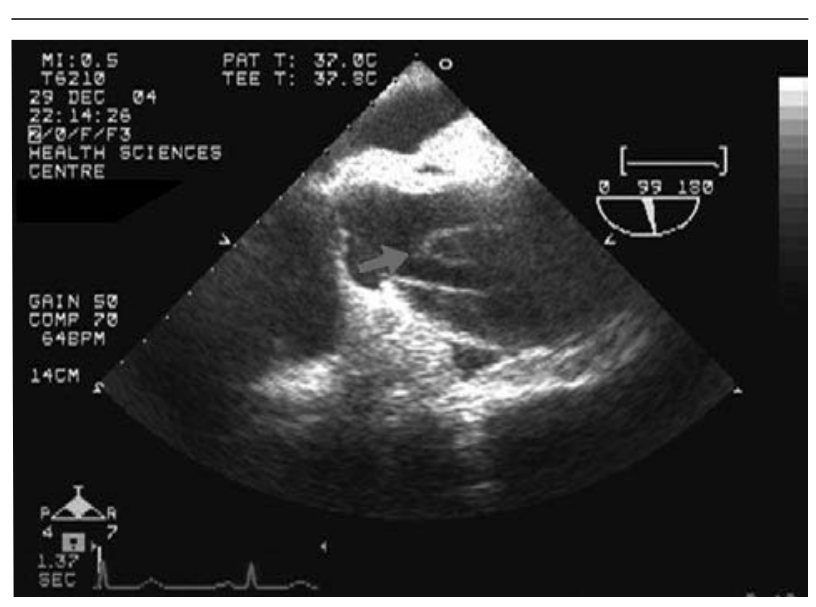

FIGURE 1 Transesophageal echocardiography image demonstrating a dissection flap (arrow). Evidence of aortic dissection was seen $4 \mathrm{~cm}$ above the sinotubular ridge.

Monitoring devices included bispectral index, an arterial line (established pre-induction) a double-lumen central venous line, a transesophageal echocardiography probe, nasopharyngeal temperature probe, and foley catheter (established post-induction). The central venous pressure measured $23 \mathrm{mmHg}$ ten minutes postinduction. Transesophageal echocardiography confirmed an acute aortic dissection (Figure 1) with a visible dissection flap (Figure 2). The dissection originated at a point $4 \mathrm{~cm}$ above the sinotubular ridge. There was no evidence of aortic insufficiency. Ventricular and valvular function were globally normal.

Repair of the acute ascending aortic dissection proceeded after cannulation of the femoral artery and two-stage venous cannulation of the inferior vena cava. Cardiopulmonary bypass was instituted and retrograde cardioplegia was administered. Unfortunately, the dissection extended to the aortic cross clamp, positioned just proximal to the innominate artery. Therefore, moderate hypothermic circulatory arrest was required for insertion of the $28-\mathrm{mm}$ Hemashield $^{\mathrm{TM}}$ tube graft.

Loading doses of phenytoin $10 \mathrm{mg} \cdot \mathrm{kg}^{-1}$ and sodium thiopental $8 \mu \mathrm{g} \cdot \mathrm{kg}^{-1}$ were administered immediately prior to circulatory arrest, achieving a bispectral index of 0 . The CPB prime included aprotinin 2 million KIU and methylprednisolone $1 \mathrm{~g} i \mathrm{v}$. Duration of CPB was $150 \mathrm{~min}$, aortic cross-clamp was $107 \mathrm{~min}$, and the duration of moderate hypothermic $\left(\mathrm{T}_{\min } 24.1^{\circ} \mathrm{C}\right)$ circulatory arrest was $21 \mathrm{~min}$. The patient was re-warmed, spontaneously assumed normal sinus rhythm, and was weaned from CPB uneventfully. Transesophageal echocardiography again demonstrated normal ventricular and valvular function. 


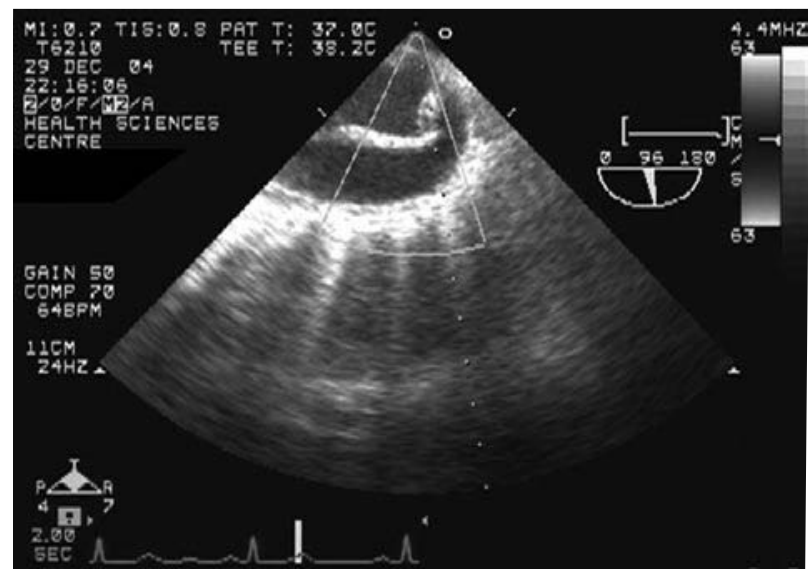

FIGURE 2 Transesophageal echocardiography cross-sectional image of the descending aorta. Doppler imaging (not demonstrated) confirmed the true (top) and false (bottom) lumens

Reversal of residual heparin effect was achieved with protamine $30 \mathrm{mg} i \mathrm{v}$ (post-protamine ACT $=163 \mathrm{sec}$ ). Subsequently, rFVIIa $90 \mu \mathrm{g} \cdot \mathrm{kg}^{-1}$ was administered. Post-bypass, the patient received small boluses of phenylephrine and ephedrine which successfully maintained her mean arterial pressure $>60 \mathrm{mmHg}$. At the end of surgery her arterial blood values were normal: $\mathrm{pH} 7.31, \mathrm{PaO}_{2} 245 \mathrm{mmHg}, \mathrm{PaCO}_{2} 31.2 \mathrm{mmHg}$, $\mathrm{HCO}_{3}^{-} 15.4 \mathrm{mEq} \cdot \mathrm{L}^{-1}$, base excess -9.5 , hemoglobin $85 \mathrm{~g} \cdot \mathrm{L}^{-1}$. Urine output was $160 \mathrm{~mL}$ for the case duration. Combined mediastinal and posterior pericardial chest tube losses were $<100 \mathrm{~mL}$.

The patient was transported to the surgical intensive care unit postoperatively where mechanical ventilation was continued. Four hours later, the patient opened her eyes spontaneously, and was able to move all four extremities to command. Her trachea was extubated $12 \mathrm{hr}$ postoperatively. The next day she was transferred to a step-down unit, with no apparent neurologic or cognitive deficits. Combined chest tube losses were $460 \mathrm{~mL}$ and $240 \mathrm{~mL}$ on postoperative days one and two, respectively. The remainder of her postoperative course was uneventful. Of note, 40,000 U albuminfree erythropoietin was administered on postoperative day one, and iron sulfate $300 \mathrm{mg}$ po tid was prescribed. Phlebotomy was deliberately avoided postoperatively. Her hemoglobin concentration was $82 \mathrm{~g} \cdot \mathrm{L}^{-1}$ at the the time of discharge on the seventh postoperative day. At a three month follow-up visit, the patient reported no sequelae related to her surgery.

\section{Discussion}

Perioperative bleeding is an important contributor to morbidity and mortality in cardiac surgery patients. Significant bleeding occurs in 5 to $30 \%$ of patients who require $\mathrm{CPB} .{ }^{8}$ The risk of hemorrhage is even greater in patients with type A dissections undergoing surgical repair. A retrospective study of almost 300 such patients cited a mortality rate secondary to hemorrhage of $10 \% .^{9}$ It is also known that deep hypothermic circulatory arrest increases the risk of perioperative hemorrhage. ${ }^{10}$ Recombinant factor VIIa has been used in patients, under similar settings, who experience refractory bleeding despite multiple blood product transfusions. ${ }^{7,11,12}$

The only clinically approved indication for the use of rFVIIa is for the management of hemostasis in hemophilia A and B patients with inhibitors to factors VIII and IX, respectively. ${ }^{4}$ The drug has been used successfully during several procedures reported in the surgical and trauma literature. ${ }^{5}$ Unfortunately, there are only two randomized controlled trials evaluating the use of rFVIIa in the perioperative setting. ${ }^{13,14} \mathrm{~A}$ great deal remains to be learned about the safety and efficacy of rFVIIa beyond currently-approved indications.

At the site of endothelial injury, rFVIIa, is believed to activate factors IX and X in a tissue factor-dependent manner, culminating in the production of thrombin, and subsequently, fibrin. ${ }^{6}$ The thrombin remains almost exclusively at the site of endothelial injury, avoiding systemic activation of coagulation. ${ }^{15}$ Therefore, the incidence of adverse events is quite rare. ${ }^{4}$ Regardless, rFVIIa must be used judiciously in patients who have a tendency towards activation of their coagulation systems. Risk factors include sepsis, advanced age, atherosclerotic disease, and a history of thromboembolic events. ${ }^{6}$ Thrombotic complications associated with use of rFVIIa include acute myocardial infarction, cerebral vascular accidents, disseminated intravascular coagulation, and venous thromboembolism., 4 One Canadian case-control study found a higher incidence of acute renal dysfunction in 51 patients who received rFVIIa, compared with matched controls who did not. ${ }^{16}$ One episode of intestinal gangrene in association with rFVIIa admininistration has also been reported in the literature. ${ }^{6}$

The optimal dose of rFVIIa in the perioperative setting is unknown. In trauma and surgical patients, rFVIIa doses around $90 \mu \mathrm{g} \cdot \mathrm{kg}^{-1}$ have been suggested. Although this is the approved dose for treating hemophiliac patients ${ }^{5}$ a wide dose range from 35 to 200 $\mu \mathrm{g} \cdot \mathrm{kg}^{-1}$ has been reported. ${ }^{4,6}$

The cost of rFVIIa is another controversial matter. At a cost of approximately $\$ 940.00 \cdot \mathrm{mg}^{-1}(\mathrm{Cdn})^{12}$, 
a dose of $90 \mu \mathrm{g} \cdot \mathrm{kg}^{-1}$ in an average $70 \mathrm{~kg}$ patient is slightly less than $\$ 6,000$. In controlled clinical settings, the cost must be weighed against both direct and indirect savings associated with fewer blood, platelet, and cryoprecipitate transfusions. In lifethreatening situations, pharmacoeconomic considerations may be irrelevant.

In many hospitals, the use of rFVIIa is regulated because of its cost and potential for thrombotic complications. ${ }^{4}$ In our institution, neither a hematology nor a transfusion medicine consult is required for rFVIIa administration. We chose to administer rFVIIa after discussion with the cardiac surgeon, because the patient was at high risk for a perioperative coagulopathy, and to maximize postoperative hemostasis in an effort to avoid blood transfusion due to her religious beliefs. The urgent nature of the case precluded erythropoietin and acute normovolemic hemodilution. These blood conservation strategies have been described previously in JW patients undergoing cardiac surgery. ${ }^{17} \mathrm{We}$ recognize that preemptive use of rFVIIa in this setting was an "off label" indication. However, all case reports involving rFVIIa administration in nonhemophiliac patients fall outside the drug's one clinically-approved indication.

In conclusion, we report a favorable outcome and notable absence of neurologic sequelae in an elderly patient scheduled for repair of a type A aortic dissection, requiring hypothermic circulatory arrest. The patient refused transfusion of blood products for religious reasons. Following cardiopulmonary bypass, rFVIIa was administered to avert a potential postoperative coagulopathy associated with $\mathrm{CPB}$ and hypothermic arrest. The prophylactic perioperative use of $\mathrm{rFVIIa}$ to prevent coagulopathy has not been reported previously. Further investigation is warranted to determine the potential role of rFVIIa in this high-risk setting.

\section{References}

1 Shiono M, Hata M, Sezai A, Negishi N, Sezai $\Upsilon$. Surgical results in acute type A aortic dissection. Ann Thorac Cardiovasc Surg 2005; 11: 29-34.

2 Hagan PG, Nienaber CA, Isselbacher EM, et al. The International Registry of Acute Aortic Dissection (IRAD). New insights into an old disease. JAMA 2000; 283: 897-903.

3 Wilde JT. Hematological consequences of profound hypothermic circulatory arrest and aortic dissection. J Card Surg 1997; 12: 201-6.

4 Goodnough LT, Lublin DM, Zhang L, Despotis G, Eby $C$. Transfusion medicine service policies for recombinant factor VIIa administration. Transfusion 2004; 44 : 1325-31.
5 Grounds $M$. Recombinant factor VIIa (rFVIIa) and its use in severe bleeding in surgery and trauma: a review. Blood Rev 2003; 17: S11-21.

6 Midathada MV, Mehta P, Waner M, Fink LM. Recombinant factor VIIa in the treatment of bleeding. Am J Clin Pathol 2004; 121: 124-37.

7 Vanek T, Straka Z, Hrabak J, Jares M, Brucek PJ, Votava J. Use of recombinant activated factor VII in cardiac surgery for an effective treatment of severe intractable bleeding. Jpn Heart J 2004; 45: 855-60.

8 McCusker K, Lee S. Post cardiopulmonary bypass bleeding: an introductory review. J Extra Corpor Technol 1999; 31: 23-36.

9 Pansini S, Gagliardotto PV, Pompei E, et al. Early and late risk factors in surgical treatment of acute type A aortic dissection. Ann Thorac Surg 1998; 66: 779-84.

10 Mangano CT, Neville MJ, Hsu PH, Mignea I, King J, Miller DC. Aprotinin, blood loss, and renal dysfunction in deep hypothermic circulatory arrest. Circulation 2001; 104(suppl I): I-276-81.

11 Egan JR, Lammi A, Schell DN, Gillis J, Nunn GR. Recombinant activated factor VII in paediatric cardiac surgery. Intensive Care Med 2004; 30: 682-5.

12 Naik VN, Mazer CD, Latter DA, Teitel JM, Hare GM. Successful treatment using recombinant factor VIIa for severe bleeding post cardiopulmonary bypass. Can J Anesth 2003; 50: 599-602.

13 Friederich PW, Henny CP, Messelink EJ, et al. Effect of recombinant activated factor VII on perioperative blood loss in patients undergoing retropubic prostatectomy: a double-blind placebo-controlled randomised trial. Lancet 2003; 361: 201-5.

14 Lodge JP, Jonas S, Oussoultzoglou E, et al. Recombinant coagulation factor VIIa in major liver resection. Anesthesiology 2005; 102: 269-75.

15 Hendriks HG, van der Maaten JM, de Wolf J, Waterbolk $T W$, Slooff MJ, van der Meer J. An effective treatment of severe intractable bleeding after valve repair by one single dose of activated recombinant factor VII. Anesth Analg 2001; 93: 287-9.

16 Karkouti, K, Beattie WS, Wijeysundera DN, et al. Recombinant factor VIIa for intractable blood loss after cardiac surgery: a propensity score-matched casecontrol analysis. Transfusion $2005 ; 45$ : 26-34.

17 Loubser PG, Stoltz SM, Schmoker JD, et al. Blood conservation strategies in Jehovah's Witness patients undergoing complex aortic surgery: a report of three cases. J Cardiothorac Vasc Anesth 2003; 17: 528-35. 